\title{
A RARE CASE OF GALLBLADDER PERFORATION WITH CONCOMITANT SUPERIOR MESENTERIC ARTERY THROMBOSIS CAUSING BOWEL ISCHEMIA
}

Minakshi Gadhire ${ }^{1}$, Chetan Rathod ${ }^{2}$, Mohan Joshi' ${ }^{3}$, Jaskaran Singh Saini' ${ }^{4}$, Gaurav Mishra ${ }^{5}$

\section{HOW TO CITE THIS ARTICLE:}

Minakshi Gadhire, Chetan Rathod, Mohan Joshi, Jaskaran Singh Saini, Gaurav Mishra. "A Rare Case of Gallbladder Perforation with Concomitant Superior Mesenteric Artery Thrombosis causing Bowel Ischemia". Journal of Evolution of Medical and Dental Sciences 2014; Vol. 3, Issue 03, January 20; Page: 678-680, DOI:

$10.14260 /$ jemds/2014/1885

\begin{abstract}
We are presenting a rare case of Gall Bladder Perforation with Superior Mesenteric Artery thrombosis causing mid gut gangrene. Gall bladder Perforation due to gallstones and Acute Mesenteric Ischemia are two different pathologies not associated with each other, occurring together in the same patient causing acute abdomen has not been reported in the literature till date.
\end{abstract}

INTRODUCTION: Gall Bladder perforation with superior mesenteric artery thrombosis causing midgut gangrene are two different pathologies occurring in a patient at same time presenting as an acute abdomen is a rare case. There is no such case reported in the literature of these two different diseases occurring together at a time in a patient. Incidence of isolated Gall Bladder perforation is reported as 3 $\%$ in cases of acute cholecystitis with mortality ranging from 12 to $16 \% 1$. Superior mesenteric artery ischemia is due to sudden hypoperfusion of small intestine leading eventually to small bowel gangrene. Acute mesenteric ischemia is a lethal disease due to delay in diagnosis by virtue of its nonspecific clinical presentation. Incidence of both the pathologies in a single patient has not been documented till date, however awareness of condition with high index of suspicion and early intervention is needed as emphasized in our case.

CASE REPORT: A 65 year old male presented to emergency department with gradually increasing pain in right upper quadrant since 2 days, dull aching in nature associated with multiple episodes of bilious vomiting but no fever, jaundice. Patient also complained of oliguria since 2 days. Patient had similar complaints a month back but relieved after medication. He had no significant past medical or surgical history.

At presentation, patient was afebrile but had tachycardia of 120/min and BP of 100/70 mm Hg. His abdomen was tender in right upper quadrant but showed no rigidity or guarding. There was leukocytosis (13000/cumm) with normal alkaline phosphatase and amylase levels. Liver and renal functions were within normal range. Ultrasonography showed cholecystitis with pericholecystic fluid and a single large calculus impacted at the neck of the gall bladder. Conservative line of management was started in view of above findings.

However, patient's condition worsened on Day 2 with abdomen now tender as well as guarded and no improvement in vital parameters. Suspecting gall bladder perforation an urgent C.T.scan was advised, which apart from showing gall bladder perforation near fundus also showed superior mesenteric artery occlusion with thickened edematous small and large bowel [Fig-1].

Patient was taken up for an urgent exploratory laparotomy after adequate resuscitation. Intra operative findings were gangrenous bowel starting around 8 inches from duodeno-jejunal flexure till middle of transverse colon and Gall Bladder perforation at fundus, $10 \mathrm{~mm}$ in size, with omentum and 
transverse colon adherent to the perforation site and 1.5 litre of hemorrhagic fluid [Fig2].Cholecystostomy was performed due to adhesions in Callot's triangle making it difficult to do cholecystectomy. Resection of gangrenous bowel was done with a jejunal end stoma and transverse colon mucous fistula brought out. Intra operatively patient was started on inotropic supports which were continued post operatively as well along with ventilatory support. Patient continued to remain on inotropic and ventilator support with no clinical improvement and succumbed on post-operative day 7 of surgery.

DISCUSSION: Gall bladder perforation is a rare but life threatening condition. According to Neimeeir classification, our case was type 2 gall bladder perforation. It is associated with mortality ranging from 12 to $16 \%$.

Superior mesenteric arterial occlusion leading to bowel gangrene, in our case Occlusive Mesenteric Arterial Ischemia, can be caused due to thrombosis or embolism is a surgical emergency mandating prompt diagnosis and therapy in the form of exploratory laparotomy with possible arterial reconstruction; embolectomy, thrombectomy; and/or bowel resection. The difficulty of early diagnosis is probably the most important cause of the high mortality rate exceeding $60 \% 2$.

There is one case reported of ischemic gall bladder perforation where there was celiac artery and superior mesenteric artery thrombosis leading to gallbladder perforation ${ }^{3}$. In this patient the etiology was same for both the pathologies unlike our patient where two different pathologies existed.

Both gall bladder perforation and acute mesenteric ischemia are rare but important differential diagnosis of acute abdomen, which due to their non-specific clinical presentation can and are often confused with acute pancreatitis, duodenal ulcer perforation etc. However, prompt diagnosis is a necessity for which C.T. Scan has surpassed other modalities as choice of investigation in acute mesenteric ischemia but only $50 \%$ of Gall Bladder perforations were picked up ${ }^{4}$. Early intervention is required in both conditions to limit morbidity and mortality and a more favorable outcome.

We conclude that increased awareness and high degree of suspicion are required for prompt diagnosis and management of both, gall bladder perforation and acute mesenteric ischemia. We want to highlight the importance of early CT scan to diagnose these conditions early, so that early surgical treatment can be commenced, which helps in decreasing the morbidity and mortality.

\section{REFERENCES:}

1. Simmons TC, Miller C, Weaver R. Spontaneous gallbladder perforation. Am Surg 1989; 55: 311-13.

2. Betzler M. Surgical technical guidelines in intestinal ischemia. Chirurg 1998; 69: 1-7

3. T.Vancauwenberghe, F.M.Vanhoenacker, L. Verheyen. Ischemic gallbladder Perforation. JBR-BTR 2011; 94: 152-53

4. Kim PN, Lee KS, Kim IY, Bae WK, Lee BH. Gallbladder perforation: comparison of US findings with CT. Abdomen Imaging 1994; 19: 239-42. 

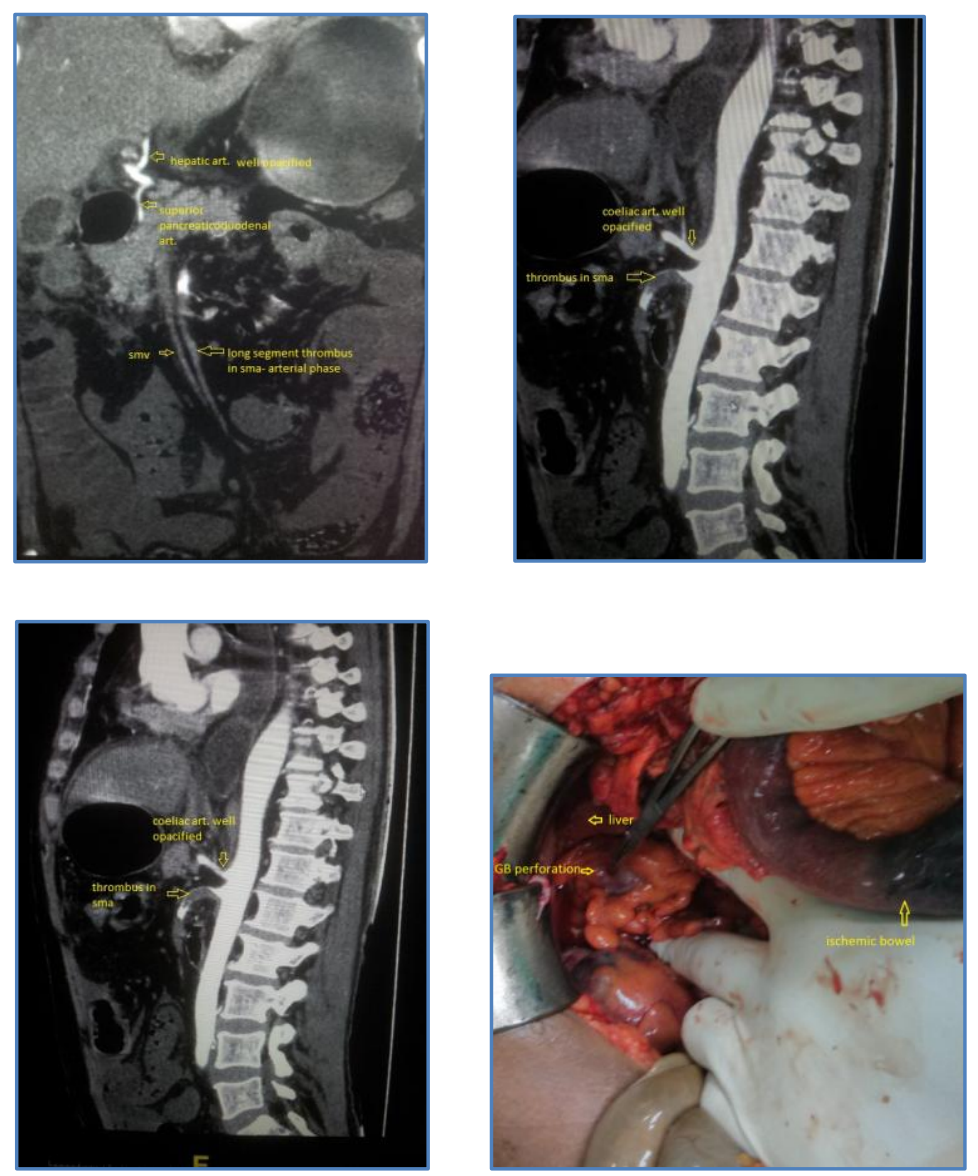

Intra 0p.

\section{AUTHORS:}

1. Minakshi Gadhire

2. Chetan Rathod

3. Mohan Joshi

4. Jaskaran Singh Saini

5. Gaurav Mishra

\section{PARTICULARS OF CONTRIBUTORS:}

1. Associate Professor, Department of Surgery, Lokmanya Tilak Municipal Medical College and Hospital, Sion, Mumbai.

2. Assistant Professor, Department of Surgery, Lokmanya Tilak Municipal Medical College and Hospital, Sion, Mumbai.

3. Professor, Department of Surgery, Lokmanya Tilak Municipal Medical College and Hospital, Sion, Mumbai.
4. $3^{\text {rd }}$ Year Resident, Department of Surgery, Lokmanya Tilak Municipal Medical College and Hospital, Sion, Mumbai.

5. Assistant Professor, Department of Surgery, Lokmanya Tilak Municipal Medical College and Hospital, Sion, Mumbai.

\section{NAME ADDRESS EMAIL ID OF THE CORRESPONDING AUTHOR:}

Dr. Chetan Rathod,

A/35, $3^{\text {rd }}$ Floor,

Naik Nagar Co-Op Housing Society,

Shiv Shursthi, S.G. Brave Marg, Kurla [East],

Mumbai - 400024, Maharashtra.

Email -drchetanrathod@gmail.com

Date of Submission: 20/12/2013.

Date of Peer Review: 21/12/2013.

Date of Acceptance: 03/01/2014.

Date of Publishing: 16/01/2014. 